\title{
El discreto Galateo: \\ Cortesía, discreción, disimulo y medro social en la obra de Lucas Gracián Dantisco ${ }^{1}$
}

\author{
Miguel Cerezo Alberdi \\ Universidad Autónoma de Madrid \\ miguelcerezoalberdi@hotmail.com
}

Recibido: 16 de mayo de 2011

Aceptado: 22 de enero de 2014

\begin{abstract}
Resumen
Galateo Español, adaptación hispana del Galateo overo de 'costumi, fue uno de los tratados de conducta de mayor y prolongado éxito. No obstante, la verdadera dimensión del pragmatismo y utilidad para la vida áulica del peculiar sello de Gracián Dantisco no ha sido aún suficientemente considerado. Mediante una lectura que otorgue atención debida al papel jugado por la discreción, hábito conductor del comportamiento, hallaremos las técnicas y medios que permiten la supervivencia cortesana como el paso al disimulo o la prevención contra la lisonja. Una visión que, en última instancia, viene a reconsiderar algunos planteamientos historiográficos que ven en ella una obra de "tono menor" o "ingenua cortesía".
\end{abstract}

Palabras clave: Galateo, buenas maneras, discreción y disimulo.

\section{The discreet Galateo: Courtesy, Discretion, Concealment and Social Promotion on Lucas Gracián Dantisco's work}

\begin{abstract}
Galateo Español, Spanish adaptation of Galateo overo de'costumi, was one of the most successful and widely read treatises of behavior. Nevertheless, the true dimension of the pragmatism and usefulness for Court Life of Gracian Dantisco's version hasn't been praised enough. Through a reading that pays due attention to discretion as the main guiding principle, we will find the techniques and means that enable courtiers' survival, like the "Way to Concealment" and the "Prevention towards flattery". A view that, finalally, reconsiders some historiographical approaches that have regarded it as a work of "tono menor" or of "naive courtesy".
\end{abstract}

Key words: Galateo, good manners, discretion and concealment.

1 El presente estudio es el resultado de una investigación cuyas líneas principales fueron ya presentadas en el Colégio do Espírito Santo-Universidad de Évora durante el Seminário Interuniversitário "Identidade, construção da memória e cultura de corte: A aristocracia hispana. Séculos XVI-XVIII" organizado por CIDEHUS (UE), Universidad Autónoma de Madrid y Universidad de Cantabria en junio del 2010. A estas instituciones quisiera agradecer la enorme deuda personal y académica contraída durante todos estos años, y, con especial atención, a los profesores Antonio Álvarez-Ossorio e Ignacio Atienza Hernández por su dirección, inspiración y constante apoyo. 
Acaecía en Verona, ciudad de Italia, la supuesta historia ejemplar. Residía allí el sabio obispo Joan Matheo Gilberto, él cual, "entre otras sus loables costumbres, fue muy cortés y liberal, honrando en su casa a los gentileshombres passageros, con aquella medianía de aparato que a su estado convenía"'. Sucedió así que entre ellos se alojó el Conde Ricardo, discreto gentilhombre y caballero nobilísimo, al que por su trato y comunicación agradable le tomaron en casa del obispo mucho precio y estima. Pronto halló el obispo un pequeño, pero desagradabilísimo, defecto en las costumbres de su invitado. Como con el tiempo todos llegaron a percibirlo, no quiso el obispo que marchase de allí sin que previamente se le avisara de aquello. Para propiciar una ocasión en que el Conde no sufriese gran vergüenza, mandó que el día de su marcha, so pretexto de darle debida despedida, éste fuese acompañado durante un buen trecho del camino por uno de sus más discretos criados, Galateo, quién, al separarse, le habría de dar con rostro alegre y dulces palabras el siguiente recado:

Señor mío, el Obispo mi señor me mandó diesse a Vuestra Señoría de su parte las gracias de la merced que le ha hecho por haverse querido servir de su casa, y en recompensa de tanta cortesía, me mandó que yo os hiziesse un presente, y os suplica mucho le recibáis con ánimo agradable. Y el don es éste: Vos, Señor, sois el más discreto, gallardo y gracioso cavallero de quantos he visto ni tratado. Por el qual, haviendo con buena atención examinado vuestra manera de proceder, no halla en vos cosa que no sea sumamente digna de loor, fuera de un acto o ruido disforme que hazéis con los labios y con la boca mazcando, a la mesa, que es muy desapazible; y os embía a suplicar recibáis en lugar de don esta amable reprehensión y advertimiento, y os haze cierto que no hay otro alguno en el mundo que tal ni tan buen presente os haga ${ }^{2}$.

A buen seguro, el lector cortesano tomaría buen aviso de esta historia en que, personificado sobre la figura del imaginario y homónimo criado, Galateo Español trasmitía, breve y ejemplarmente, las esencias de lo que habría de ser el resultado de las enseñanzas del tratado. Por un lado quedaba la prevención hecha al Conde, el cual, un poco colorado por lo oído, daba por muy bueno el consejo que el dicho criado le estaba dando, considerando "que si assí fuessen todos los presentes que los hombres se hazen unos a otros como el suyo, ellos serían harto más ricos de lo que son" Mientras que del otro lado, aunque menos obvia, quedaba una segunda e importante enseñanza emanada de las sutiles maneras con que el criado, cuidando al máximo su expresión física y verbal, lograba encaminar tan delicado cometido sin dejar de resultar agradable a ojos del reprendido. En ambas advertencias, y no solamente en aquella peculiar forma de enriquecimiento, se encuentra la razón de ser de la obra que nos ocupa. Únicamente la hábil combinación de ellas haría que lector y conde pudiesen ser recibidos en el seno de la sociedad cortesana sin que, debido a algún hábito grosero o unas rudas maneras, mermase en algo la distinción y notoriedad que por su buena crianza, la nobleza de linaje y la extensión de sus haciendas mereciesen.

1 Gracián Dantisco, L.: Galateo Español [Estudio preliminar, edición, notas y glosario por Margherita Morreale], Madrid, Consejo Superior de Investigaciones Científicas, 1968, p. 110.

2 Ibidem, p. 110.

3 Ibidem, pp. 110-111. 
Ciertamente, este dominio de los códigos de buenas maneras como vehículo para el incremento o refuerzo del prestigio social propuesto por obras tales como Galateo Español no resulta ajeno a la historiografía, que ha tratado ampliamente este género desde que la pionera obra del sociólogo Norbert Elias llamara la atención sobre ello. $\mathrm{Su}$ reinterpretación de la sociedad cortesana bajo la evidencia de la inexistencia de una distinción de espacios públicos y privados permitió que cobrase importancia el estudio de aspectos como el ceremonial, la etiqueta o la magnificencia suntuaria, los cuales guardaban una correlación con respecto a la posición ocupada en la sociedad. Posteriormente, desarrollando y matizando algunos de los ejes marcados por el sociólogo alemán, la historiografía ha redoblado sus esfuerzos para llegar a una mayor compresión del papel jugado por el mundo áulico en la configuración política y modelación de conductas, pudiendo distinguirse dos grandes focos, británico e italiano, como claves en esta investigación. La historiografía anglosajona, encabezada por la Society for Court Studies, se ha interesado tanto en la Corte como en la cultura nobiliaria ${ }^{4}$. Pero es en Italia, a partir del Centro studi sulle società di antico regime "Europa delle Corti", donde se ha vivido una nuevo salto metodológico al abordar el estudio de la sociedad de Corte desde perspectivas antropológicas, lo que ha permitido poner en relieve la importancia que tiene entender la modelación de comportamientos desde aquellos valores inherentes a la propia cultura cortesana. El éxito obtenido desde diversas perspectivas, artísticas, históricas y filológicas puede apreciarse en trabajos como los de Amedeo Quondam o Cesare Mozzarelli ${ }^{5}$. Siguiendo el impulso de ambos grupos, desde la década de los noventa han ido apareciendo en España estudios que versan sobre la organización, mentalidad, comunicación y comportamiento de la nobleza ${ }^{6}$. Sobre su papel desempeñado en la corte, etiquetas y organización de

4 Las aportaciones interpretativas de la historiografía anglosajona sobre la Corte han sido relevantes por su número y la calidad de sus estudios por lo que aquí nos limitaremos a poner algunos ejemplos. Sobre la corte: Dickens, A. G. (ed.): The Courts of Europe, Politics, Patronage and Royalty 1400-1800, Londres, Thames \& Hudson, 1977; STARkey, D. y otros: The English Court from the War of the two Roses to the Civil War, Londres, Logman, 1987; Asch, R. y Birke, A. (dirs.): Princes, Patronage and the Nobility. The Court at the beginning of Modern Age, Oxford University Press, Oxford, 1991.

5 Los comienzos de la historiografía sobre la Corte en Italia se abordaron en el congreso dirigido por Mozzarelli, C. y Olmi, G. (eds.): La corte nella cultura nella storiografia, Immagini e posizioni tra Otto e Novecento, Roma, Bulzoni, 1983; posteriormente otros estudios concedieron a la Corte categoría historiográfica: Bertelli, G: Le corti Italiane del Rinascimento, Milán, A. Mondadori, 1985; Mozzarelli, C.: "Prince and Court: Why and How Should the Court be Studied today", Schifanoia, 8 (1989), pp. 33-36 y Mozzarelli, C.: (ed.), "Familia" del príncipe e famiglia aristocrática, Roma, Bulzoni 1988; Mozzarelli, C. y VENTURI, G: L'Europa della Corti alla fine dell'antico regime, Roma, Bulzoni, 1991. Posteriormente, QuONDAM, A.: Il libro a Corte, Roma, Bulzoni, 1994; Questo povero Cortegiano Castiglione, il libro, la storia, Roma, Bulzoni, 2000; ó Patrizi, G. y Quondam, A. (dirs.): Educare il corpo, educare la parola nella trattatistica del Rinascimento, Roma, Bulzoni, 1998; Boteri, I.: Galateo e Galatei. La creanza e l'istituzione della societá nella trattatistica italiana tra antico regime e stato liberale. Roma, Bulzoni, 1999.

6 Carrasco Martínez, A.: Sangre, honor y privilegio. La nobleza española bajo los Austrias, Barcelona, Editorial Ariel, 2000. Sobre la identidad: Guillén BARREndero, J. A.: La idea de nobleza en Castilla durante el reinado de Felipe II, Valladolid, Universidad de Valladolid, 2007. Sobre la organización de la casa nobiliaria: Atienza Hernández, I.: Aristocracia, poder y riqueza en la España Moderna. La Casa de Osuna, siglos XVXIX, Madrid, Siglo XXI de España, 1987; Salas Almeda, L.: Medina Sidonia. El poder de la aristocracia, 1580-1670, Madrid, Marcial Pons, 2008. Sobre la comunicación, comportamientos y el aprendizaje a través de tratados: Carrasco Martínez, A: "Fisionomía de la virtud. Gestos, movimientos y palabras en la cultura cortesano-aristocrática del siglo XVII", Reales Sitios, 147 (2001), pp. 26-37; BouZA Álvarez, F.: Imagen y 
la misma ${ }^{7}$. Y, de la misma manera, estudios sobre diversos elementos afines al mundo áulico (como los ceremoniales y rituales, el coleccionismo, los libros, la música, las carrozas, etc.) nos permiten conocer con mayor precisión la sociabilidad aristocrática que caracterizó la vida de las cortes hispanas en época moderna ${ }^{8}$.

No obstante, como se puede observar por la variedad de enfoques y objetos de los estudios antes referidos, de su mismo auge declina la cuestión sobre dónde hallan delimitación los espacios, grupos o comportamientos que habremos de considerar implicados dentro de la cultura de Corte. El género de la literatura áulica a la que pertenece Galateo Español lejos de brindar alguna respuesta no hace sino dar testimonio de esta misma disparidad. Así las cosas, mientras Alonso Núñez de Castro titulaba orgullosamente su célebre obra con el lema Solo Madrid es Corte y el Cortesano en Madrid, Luis de Milán, con la declarada voluntad de sustituir a la obra del conde mantuano en las manos de una dama, escribió Libro intitulado el Cortesano en el cual, por medio de historias de galanteos y ejemplos de cómo hacer burlas a la manera de palacio, transforma la valenciana corte virreinal del Duque de Calabria y la Reina Germana en una nueva Corte de Urbino en la que impera el ingenio ${ }^{9}$. Des-

propaganda. Capitulos de historia cultural del reinado de Felipe II, Madrid, Akal, 1998; Comunicación, conocimiento y memoria en la España de los siglos XVI y XVII, Salamanca, Seminario de Estudios Medievales y Renacentistas, 1999; Palabra e imagen en la corte. Cultura oral y visual de la nobleza en el Siglo de Oro, Madrid, Abada, 2003; Álvarez-Ossorio Alvariño, A.: "El cortesano discreto: itinerario de una ciencia áulica (ss. XVI-XVII)", Historia Social, 28 (1997), pp. 26-37; "Corte y cortesanos en la monarquía de España”en PATRIZI, G. y QuONDAM, A. (dirs.): Educare il corpo, educare la parola nella trattatistica del Rinascimento, Roma, Bulzoni, 1998; "La discreción del cortesano", Edad de Oro, Vol.18 (1999), pp. 9-45; "Proteo en Palacio. El arte de la disimulación y la simulación del cortesano", en Moran, M. y García, B. J. (eds.): El Madrid de Velázquez y Calderón y corte en el siglo XVII, Madrid, Fundación Caja Madrid, 2000; Torres CorominAs, E.: "El Cortesano de Castiglione: Modelo antropológico y contexto de recepción en la corte de Carlos V" en Martínez Millán, J. y Rivero Rodríguez, M. (coords.): Centros de poder Italianos en la Monarquía Hispánica (siglos XV-XVIII), Madrid, Polifemo, 2010, vol. 2, pp. 1183-1234.

7 Un trabajo excelente y revelador fue la obra colectiva Martínez Millán, J. (dir): La Corte de Felipe II, Madrid, Alianza, 1998. A partir del trazo de breves biografías de diversos personajes de la corte del rey prudente se esbozaba una heterogénea pero completa visión del universo cortesano. Posteriormente, la obra ha encontrado su eco en los magníficos trabajos de MarTínez Hernández, S: El Marqués de Velada y la corte en los reinados de Felipe II y Felipe III: nobleza cortesana y cultura política en la España del Siglo de Oro, Valladolid, Junta de Castilla y León, Consejería de Cultura y Turismo, 2004; Rodrigo Calderón la sombra del valido: privanza, favor y corrupción en la corte de Felipe III, Marcial Pons, Madrid, 2009. Mientras, el Instituto Universitario de la Corte en Europa ha puesto en valor la trascendencia de la Casa Real y cómo, a partir de ella, se articularon las diferentes estructuras del servicio regio que hicieron posible la gobernación de una extensa monarquía. Véanse: Martínez Millán, J. (dir.): La monarquía de Felipe II: La Casa del Rey, Madrid, Fundación Mapfre, 2005; La monarquía de Felipe III: La Casa del Rey, Madrid, Fundación Mapfre, 2009.

8 Algunos ejemplos de tan diversos enfoques son: Río BARRedo, M. J.: Madrid, Urbs Regia. La capital ceremonial de la Monarquía Católica, Madrid, Marcial Pons, 2000; CheCa Cremades, F. y Morán Turina, M.: El coleccionismo en España: de la cámara de las maravillas a la galería de pinturas, Madrid, Cátedra, 1985; BRown, J.: El triunfo de la pintura. Sobre el coleccionismo cortesano en el siglo XVII, Madrid, Editorial Nerea, 1995; García García, B. J. y Carreras Ares, J. J. (eds.): La Capilla Real de los Austrias. Música y Ritual de corte en la Europa Moderna, Madrid, Fundación Carlos de Amberes, 2001; López Álvarez, A: Poder, lujo y conflicto en la Corte de los Austrias. Coches, carrozas y sillas de mano, 1550-1700, Madrid, Polifemo, 2007. Esta pequeña muestra no es ni mucho menos completa, para un estudio exhaustivo de la historiografía de la Corte véase VÁzquez Gestal, P: El espacio de poder. La corte en la historiografía modernista española y europea, Valladolid, Universidad de Valladolid, 2005.

9 NúÑEz DE CASTRO, A.: Libro histórico político solo Madrid es corte y el cortesano en Madrid, Madrid, 1658; MiLÁn, L. de; Libro intitulado el Cortesano, Valencia, 1561. 
marcándose mucho de ambos, en El Estudioso de la Aldea, Juan Lorenzo Palmyreno sorprendía y, tras lamentarse repetidas veces por lo dificultoso de formarse tan alejado de la ciudad, terminaba instruyendo en cortesanía a su rústico aprendiz, siendo su cortesano no como el de Castiglione "sino un docto moço, contrario al grossero y suzio" ${ }^{10}$. Si bien la denominación de todos ellos como cortes y sus protagonistas como cortesanos entraña cierta polémica, menos cuestionable resulta que todos éstos, aún siendo muy distintos en honor y riqueza, comparten un sistema organizativo en torno a un señor o pater familias cuya relación con familiares, criados, vasallos y otros deudos se encuentra sustentada en el mismo código de servicio-merced en el cual estaba basada la sociedad cortesana. La ciencia de la cortesanía y por ende la literatura áulica nacía con el objetivo de perfeccionar aquellos comportamientos que posibilitaban el acceso al favor del Señor, al premio de la gracia y al pago mediante mercedes de los servicios prestados al superior. Así pues, lo que en última instancia parece aglutinar la infinidad de situaciones, lugares o comportamientos impregnados de este espíritu cortesano es una misma lógica de la conservación y del medro de todo aquel dispuesto a maximizar los beneficios de dicho código servicio-merced, allá dónde se diera.

Esta concepción de cortesanía, mucho más amplia que el aristocrático y virtuoso modelo de Castiglione, fue la predominante en la literatura áulica hispánica, que comúnmente se abrió hacia las desventuras de un cortesano cuyo perfil resultaba mucho más modesto y humanista ${ }^{11}$. Tal objetivo se desprende claramente en el prólogo dirigido al "curioso lector" con que Lucas Gracián Dantisco venía a incorporarse, mediante la adaptación al castellano del clásico de Giovanni Della Cassa, a un género que estaba en boga desde que, bien entrado el siglo XVI, empezaran a aparecer los primeros escritos que propagaban con exactitud los comportamientos cortesanos ${ }^{12}$. La elección de adaptar el Galateo overo de' costumi resultaba todo un acierto dado que, "traduziéndolas del Galateo italiano y añadiendo al propósito otros cuentos y

10 Palmyreno, J. L.: El estudioso de la Aldea, Valencia, 1568, p. 86.

11 Álvarez-Ossorio Alvariño, op. cit. (nota 7, 1998), p. Ciertamente, este hecho propició e incluso incrementó la brecha existente con la auténtica nobleza cortesana cuyo desenvolvimiento espontáneo distaba mucho de dejarse impactar por algunas de estas obras de bajo perfil, ocasionalmente escritas por deudos, cuyos límites resultaban mucho más modestos. Resulta útil en este sentido, recalcar la conflictividad y distancia entre los mismos grupos cortesanos estudiados en el capítulo "De clara voz" de BouzA Álvarez, op. cit. (nota 7), pp. 23-65.

12 Tras la publicación en 1539 por parte de fray Antonio de Guevara, Menosprecio de Corte y Alabanza de aldea, en que tras su inicial rechazo definía con nitidez las relaciones sociales que regían el mundo áulico, los escritos se hicieron numerosos. El mismo Guevara publicó el Libro llamado aviso de privados, y doctrina de cortesanos en 1539. Otros ejemplos pueden ser: la publicación en 1547 por parte de Cristóbal de Castillejo de Aula de Cortesanos o diálogo de la vida de la Corte; las instrucciones para gobernarse en la Corte de Juan de Vega a su hijo de 1548, glosadas por el Conde de Portalegre en 1592; el valenciano Libro intitulado el Cortesano de Luys Milan; El estudioso en la aldea y El estudioso cortesano de Juan Lorenzo Palminero que contiene avisos de buena crianza, conversación y discreción; en 1567 Pedro de Navarra publicaba en Zaragoza Diálogos muy subtiles y muy notables; Gallegos, secretario del Duque de Feria, componía unas coplas sobre la vida de palacio; en 1587 aparecería Filosofía Cortesana de Alonso de Barros. Por último, aunque son muchos los materiales que cabría señalar, interesa aquí no olvidar que en el año 1584 aparecía en Venecia la primera traducción española del texto original de Giovanni Della Cassa a manos del sacerdote sevillano Domingo Becerra, ni tampoco la muy anterior traducción de El Cortesano realizada por Boscán en 1534. 
cosas que yo he visto y oído"13, el vallisoletano garantizaba para sí un éxito similar al que el original cosecharía en Europa por su brillante integración de los tratados de buena conducta eclesiásticos con el nuevo arquetipo cortesano de Castiglione ${ }^{14}$. Sus historias estrambóticas y mordaces sátiras la convierten en una lectura tan fácil y amena como divertida, pero, sin embargo, de ello se deriva también que la estructura quede algo ensombrecida por la anécdota y su moraleja más evidente. Tampoco ayuda en este sentido que en numerosas ocasiones la obra parezca ir saltando y entremezclando aspectos diversos como vestimenta, higiene o arte conversatorio sin aparente orden lo que, en último término, puede hacer pasar desapercibida la total dimensión del modelo conductual propuesto.

Esta cierta incomprensión resulta claramente observable en algunas de las expresiones con que los historiadores contemporáneos que se han acercado a Galateo Español intentan rebajar las capacidades de la misma. Margherita Morreale (a quien debemos su magnífica edición crítica de la obra) se refirió a ella como una obra de cortesía de "tono menor" 15 . Otros trabajos más recientes, buscando aún extrapolar las conclusiones del modelo de Norbert Elias al ámbito hispano, consideran que se inscribe en un tipo de cortesanía "ingenua", ajena al código de la prudencia cuya amable sociabilidad no responde a una concepción defensiva estratégica de los contactos entre las personas ${ }^{16}$. Ahora bien, sin querer desmerecer en nada el mérito de estas publicaciones, a lo largo de las siguientes páginas se intentará ir desdibujando esta imagen mediante una lectura desde aquellos valores propios a la antropología cortesana que subyacen bajo la inmensidad de avisos sobre los modos de sentarse a la mesa, conversar, saludar, vestirse, etc. Desde esta renovada perspectiva, de la lectura de Galateo Español irán trascendiendo sustanciales apreciaciones hasta ahora escasamente consideradas ${ }^{17}$. Siguiendo la estela de conceptos vitales como el decoro o discreción se nos conducirá hacia los dominios del disimulo donde se habrá de evitar

\footnotetext{
13 Gracián Dantisco, op. cit. (nota 2), p. 99.

14 Respecto a su difusión europea, a la ya comentada traducción al español de Domingo Becerra, habría que sumar la de Juan de Peyrat, cuya traducción al francés fue publicada en París en 1562. Hubo luego una edición bilingüe, con una traducción distinta, en Lyon en 1573, reimpresa en 1583 y 1584 . Robert Peterson en 1576 lo tradujo al inglés y, algo más tarde, en 1609, Natán Kochhaff lo trasladaría al alemán. Traducciones latinas, reimpresiones y nuevas adaptaciones seguirían sucediéndose durante hasta bien entrado el siglo XVIII.

15 Morreale, M.: “ 'El “Galateo Español’ de Lucas Gracián Dantisco. Una obra de cortesía en tono menor”, Boletín de la Real Academia Española, 42 (1962), pp. 4-90.

16 Ampudia de Haro, F.: Las bridas de la conducta. Una aproximación al proceso civilizatorio español, Madrid, Centro de Investigaciones Sociológicas, 2007, pp. 44. Líneas que son continuadas posteriormente en Ampudia de Haro, F.: "Cortesía y prudencia: una gestión civilizada del comportamiento y de las emociones", en Tausiet, M. y Amelang, J. (eds.): Accidentes del alma. Las emociones en la Edad Moderna, Madrid, Abada Editores, 2009, pp. 123-139.

17 En un inspirador trabajo sobre las miserias que alejaban al mundo áulico de la Corte celestial Antonio Alverez-Ossorio ya señalaba, brevemente, cómo en el Galateo se vislumbraba el paso de la disimulación de los impulsos a cierta simulación por decoro: Álvarez-Ossorio Alvariño, op. cit. (nota 7, 2000), pp. 120-121. También, desde que empezara a exponer algunas de las conclusiones de este trabajo, ha visto la luz un reciente artículo que, aunque centrado mayormente en las tribulaciones de Gracián Dantisco acerca de las cortesías, presenta algunas semejanzas en su enfoque y unas conclusiones en la misma línea del aquí presentado: AmoN, S.: "Gracián Dantisco and the Culture of Secrecy in Hapsburg Spain", Ingenium. Revista de historia del pensamiento moderno, 5 (enero-junio 2011), pp. 55-75. Ambas publicaciones prestan mayor atención al contexto más amplio del impacto y contexto literario mientras que aquí nos centraremos más en la propia obra.
} 
los innumerables peligros de los acechantes camaleones y de los lisonjeros cantos de sirenas que, endulzando los oídos, conducirán al naufragio y perdición de aquel cortesano poco avisado.

\section{1. "De lo que se debe hacer y guardar...": Las claves de la cortesía y de la distinción}

En la obra de Tirso de Molina El vergonzoso en Palacio tiene lugar una curiosa escena en que Ruy Lorenzo, secretario del Duque de Aveiro, y Vasco, su lacayo, prófugos de los hombres del duque, topan en el bosque con los pastores Mireno y Tarso. Mireno, para facilitarles la huida, idea el siguiente ardid: cambiarán sus rústicas ropas por las mudas de los cortesanos. El resultado no puede resultar más desigual: mientras Tarso (al que corresponde el ingrato papel de ser el villano cómico ${ }^{18}$ sufre mil desventuras con las calzas demoniacas, Mireno toma gran compostura, lo cual no deja de sorprender al secretario:

De tal manera te asienta

el cortesano vestido, que me hubiera persuadido

a que eras hombre de cuenta

a no haber visto primero

que ocultaba la belleza

de los miembros de bajeza

de aqueste traje grosero.

Cuando viste el villano

las galas del traje noble, parece imagen del roble que ni mueve pie ni mano; ni hay quien persuadirse pueda sino que es, como sospech[a], pared, que de adobes hecha, la cubre un tapiz de seda.

Pero cuanto en ti contemplo el desenfado con que andas y el donaire con que mandas ese vestido, otro ejemplo hallo en ti más natural, que vuelve por tu decoro, llamándote imagen de oro, con la funda de sayal.

Alguna nobleza infiero que hay en ti; pues te prometo que te he cobrado el respeto que al mismo duque de Avero. ¡Hagate el cielo como él! ${ }^{19}$

\footnotetext{
18 Salomon, N.: Lo villano en el teatro del Siglo de Oro, Madrid, Editorial Castalia, 1998, pp. 20-54.

19 Molina, T. de: El vergonzoso en palacio [Edición, introducción y notas de Antonio Prieto], Barcelona, Editorial Planeta, 1982, p. 28.
} 
No hay lugar a dudas, bien intuye el secretario que algo extraño hay en el virtuoso aldeano que, socorriendo al injustamente agraviado, tal donaire y desenfado muestra, pues por sus venas, como finalmente se desvelará, corre sangre de la misma realeza portuguesa. Virtud y mérito, dotes superiores que distinguen al noble del plebeyo, son notorias en Mireno y, nada tiene de extraño, más acomodan en él las galas del traje noble que el vestir grosero de pastor. Tampoco causa mucha extrañeza en el espectador, cuando, en el tercer acto, la pluma de Tirso desvela que Lauro, el padre de Mireno, es en realidad el hijo del Gran Duque de Coimbra quién, por culpa de las insidias de un traidor, había permanecido oculto hasta que su sobrino, el rey Alfonso, descubre el engaño y le restituye. Así las cosas, en Mireno terminan por converger la nobleza de sangre y de mérito, quedando implícita la justificación de que era su oculta y espléndida cuna lo que explicaba sus extraordinarias cualidades que siempre le habían acompañado. Aunque tan perfectísimo y rocambolesco argumento sólo parece posible sobre las tablas del escenario, la realidad cotidiana resultaba más compleja pero, sin embargo, sorprendentemente similar. Al igual que ocurría en la escena, la propia dinámica de la vida cortesana exige que el personaje se presente en sociedad guardando unas debidas normas de decoro, que a su vez establecen que exista una adecuada correlación entre lo que lo se aparenta y lo que realmente se es. La moda de las galas, el brillo de las joyas, la pompa impresionante o la compañía de criados son algunos de los lujosos elementos materiales que sirven para identificar rápidamente el rango del individuo o del personaje teatral, pero no son suficientes. Ello quedaba ratificado en las continuas bufonadas y disparatadas ocurrencias con que Tarso se quejaba amargamente de tener que moverse con tan intrincadas quimeras como son las calzas cortesanas. Si bien es cierto que, como recordaba Domínguez Ortiz, "quien estudiara nuestra sociedad actual basándose en las caricaturas de la prensa humorística sacaría la conclusión de que un gran número de suegras y esposas apalean a sus yernos y maridos" ${ }^{20}$, parece innegable que, a pesar de las debidas matizaciones, el sufrimiento de Tarso pone de relieve la existencia de una barrera al ascenso social asociada a la compostura y comportamiento de las distintas calidades personales. Es decir, salirse de lo que está establecido para la condición propia implica ir desacomodado o desarmonizado y de ello no puede devenir ninguna otra consecuencia que la incomodidad propia.

En el Teatro de la Corte -célebre expresión popularizada por Guevara en Aviso de privados y doctrina de cortesanos- al vestir, igual que ocurría con Tarso y Mireno, debe hacerse con la ropa que mejor acomoda a la condición propia. El decoro, tal y como lo define Sebastián de Covarrubias, no es solamente "hermosear con gracia", sino también el "respeto y mesura que se debe tener delante de los mayores y personas graves" 21 lo cual implicará no sólo abstenerse de comportamientos vulgares y desagradables como estornudar sobre los alimentos, escupir o hurgarse la nariz, sino también el dominio de la ciencia del saber hablar o no hablar, del hacer o dejar de

20 Domínguez Ortiz, A.: Las clases privilegiadas en la España del Antiguo Régimen, Madrid, Ediciones Istmo, 1973, p.88

21 Covarrubias Orozco, Sebastián de: Tesoro de la lengua castellana o española [Edición integral e ilustrada de Ignacio Arellano y Rafael Zafra], Madrid, Editorial Iberoamericana, 2006, p. 669. 
hacer, ocultar o mostrar según la condición del interlocutor. Todos estos entresijos de gracia y decoro son los que busca perfeccionar el lector de Galateo Español por lo que, siguiendo esta misma línea, se le indica primeramente que debe "andar cada uno, según su estado y edad, porque de otra manera parece que en quererse señalar desprecia la gente" 22 . No obstante, la condición social no resultaba tan rígida sino que precisamente lo que se estaba tratando de hacer por medio de todas estas recomendaciones era dotarse de una compostura y un gusto que optimizase el resultado. Conservar una buena consideración pasa por mantener en todo momento la apariencia buscada y evitar comportamientos descuidados como recibir a los demás en ropa de cama, vestir de forma poco aseada o desproporcionada puesto que "han de ser, pues los vestidos muy assentados, y que vengan bien a las personas" y "los que tienen vestiduras duras ricas y nobles, pero mal entalladas y sin aseo, no parecen ser hechas a sus cuerpos, y dan a entender una de estas dos cosas: o que los tales no tengan ningún cuidado de sí, o que no conozcan lo que pueda ser gracia ni mesura ni cumplimiento alguno con las gentes" ${ }^{23}$. Por consiguiente, no consiste solo el lucimiento de la condición en la mera ostentación de demasiadas y ricas galas -aunque el consumo suntuario tenga una enorme importancia- sino en la proporción, en la mesura y en el acierto con el que se alcanza la armonía entre las partes y que explica el sentido de las disquisiciones sobre verdugados, calzas, etc. En contraste con esta adecuada mesura están los mentirosos en el vestir, que son aquellos a los cuáles su fortuna material les permite ostentar sin acierto de tal forma que su falta de buena crianza les termina delatando y "sobre vestidos no muy buenos, se doran de cadenas y anillos y medallas colgando de acá y de allá, que más parece que lo traen para vender, que por gala" 24 .

Un exceso de cuidado juega de nuevo en contra del pretendiente, puesto que, aún abandonando todo signo de rusticidad y vistiendo con buenas y armonizadas galas, el resultado puede ser insatisfactorio si mantener esta apariencia delata esfuerzo o artificio. El vicio de la afectación supone delatar el empeño y, por consiguiente, lo leve y vanidoso del personaje, "hallándose algunos déstos tan narcisos y satisfechos de sí, que si como se miran en espejos, se mirassen en agua, no dexarían de ahogarse" 25 . Si volvemos al ejemplar caso de Mireno, ninguna sombra de afectación había en él, pues su tan aclamado lustre lo había obtenido por su natural superior tras cambiarse la muda tras unos arbustos. Como resultaba imposible transferir por medio de una lectura la superior naturalidad, la literatura áulica, que estaba intentando enseñar lo que según el propio pensamiento de la época no respondía a enseñanza sino a la sangre, sorteaba la cuestión abogando por un cierto descuido que ocultase el arte mediante la gracia ${ }^{26}$. Así, si resultaba demasiado afectado y afeminado que el hombre se aderezase como las mujeres que se lavan con "aguas adobadas", podría sortearse la cuestión del mal olor valiéndose de esta aromática curiosidad de forma menos notoria

22 Gracián Dantisco, op. cit. (nota 2), p. 113.

23 Ibidem, p. 114.

24 Ibidem, p. 126.

25 Ibidem, p. 115.

26 Burke, P.: Los avatares de El Cortesano. Lecturas y lectores de un texto clave del espíritu renacentista, Barcelona, Gedisa, 1998, pp. 85-97. 
y con cierta desenvoltura y desparpajo como, por ejemplo, con unos buenos guantes "traídos al descuido"27.

Abandonando los usos en el vestir, conviene que estos mismos principios traídos al hilo de lo visual los traslademos a lo oral, puesto que la cultura de la conversación es uno de los elementos que mediante el uso de cortesías, saludos, insultos, etc. permitía identificar y autorreconocerse a los caballeros y damas de buena crianza y en el que más insiste la tratadística cortesana repitiéndose avisos para hablar o callar que, como todas sus reglas, tenían una indisimulada voluntad disciplinadora que actuaría tanto hacia el interior del grupo, cohesionándolo, como hacía el exterior, distinguiéndolo ${ }^{28}$. En este sentido, Galateo Español no es una excepción, es más, puede afirmarse que las normas sobre la adecuada forma de hablar constituyen la parte central del mismo. La buena manera de conversar debe transcurrir en los mismos términos de equilibrio que veíamos anteriormente y que podemos ejemplificar en la misma materia sobre la cual se platica "la qual no deve ser fría, de poca sustancia, ni baxa, y vil, porque los que la oyen, en lugar de recrearse, escarnecen de la plática, y del que la dize también" ni tampoco volverse "muy sotil ni exquisita" 29 . Incluso la misma elección de las palabras ha de ser refinada "en cuanto al sonido y su significación, buenas y hermosas", siendo más apropiado el uso de boca en vez de hocico, vientre en vez de panza, amiga en vez de ramera, etc. E igualmente, también se deben evitar las palabras afectadas, no acertando con la elección aquel que estándosele terminando la tinta del tintero escribió: "cesso, porque ya el cornerino vasso no subministra el ethiopico liquor al ansarino cálamo" ${ }^{30}$. Comparte así la opinión del Conde Ludovico en los diálogos de Urbino, que ante la preocupación porque el habla del cortesano fuera tan elegante y sustanciosa que resultase a muchos ininteligible, sentenció: "Más antes le entenderán todos porque la facilidad y la llaneza siempre andan con la elegancia"31.

De forma reiterada podemos ver cómo las pautas explícitas de buenas maneras se mueven entre los dos conceptos básicos de la gravedad del decoro y la sprezzatura. Esta misma idea se constata a lo largo de las distintas partes del tratado como las que refieren a los encarecimientos, en el modo en el que se ha de jugar, en la forma de contar los propios méritos, etc. Una sutileza ésta que, vale la pena resaltarlo, marca una enorme diferencia con otras obras de buena crianza que, al abordar los mismos tópicos, lo hacen de manera bien distinta. El lector que hubiera memorizado las sencillas coplillas de Documentos de buena crianza de Francisco Ledesma (una corta obra aparecida pocos años después y que introduce a similares preceptos) coincidiría con el lector de Galateo Español en una primera condena a la bebida, al juego o a la burla. Sin embargo, este último se distinguiría rápidamente del primero por las finezas, como diferenciar entre la mofa ofensiva y los muy cortesanos y burlescos motes o distinguiendo la diferencia que va entre el jugar afanando riquezas o el hacerlo entre personas graves y mostrando una graciosa despreocupación.

\footnotetext{
27 Gracián Dantisco, op. cit. (nota 2), p. 179.

28 Bouza Álvarez, op. cit. (nota 7, 2003), p.37.

29 Gracián Dantisco op. cit. (nota 2), p. 115.

30 Ibidem, p. 142.

31 Castiglione, B. de: El Cortesano, Madrid, 1945. pp. 138.
} 
Se debe tener en cuenta que al mismo tiempo que la nobleza insistía en identificarse a sí misma con la imagen del caballero cuyas buenas maneras le hacen distinguirse del común por su buena crianza, buscaba también, en la misma línea de reforzar su prestigio, asociar su imagen a las de bibliófilo, patrón de las artes, virtuoso político, etc. que actuaban como barrera mucho más eficaz ante advenedizos que quisieran contagiarse del honor. No es de extrañar, dado lo gravosas que podían resultar estas actividades, que se advirtiese que para ser bienquisto y amado de gente primeramente debe atenderse a oficio, cargo o asiento, o saber administrar su hacienda, que "sin ello no hay que hazer cuenta de estas reglas y documentos" 32 . La referencia a la necesidad de bolsillos desahogados es frecuente en la literatura áulica y casi nula en los tratados eclesiásticos que son más tendentes a loar las virtudes de la austeridad. Ganar el amor y el reconocimiento ajeno resultaba una actividad mucho más onerosa. Francisco de Portugal recomendaba al galán no racanear en el aguinaldo de criados y amas ya que éstos podían dificultarle mucho el acceso y la comunicación con su dama puesto que eran declarados "enemigos del poco caudal" ${ }^{33}$. Misma referencia encontramos en Antonio de Guevara quién, a su vez, avisaba al cortesano de reservar para el portero alguna pieza de seda o rica sortija si quería agilizar la audiencia con su señor y, además, que de no ser de mucha hacienda, convenía para no llegar a la ruina mantenerse a buen recaudo de las damas de palacio y de las monjas pues "el officio dela dama es pelar al que la sirve: y el dela monja pedir al que la visita" 34 . No obstante, aunque la falta de una fortuna que despilfarrar suponía un impedimento, en las recomendaciones de buenas maneras de Galateo Español subyace la idea de que el caballero de buena crianza, conocedor de los entresijos de la gracia y del decoro, sabrá maximizar sus recursos para terminar distinguiéndose al adoptar una actitud armoniosa propia de personas graves y de sustancia.

\section{2. "Para ser bienquisto": discreción y disimulo como llaves del éxito social del Galateo}

Distinguido, grave y de sustancia, nuestro caballero está en condición de entrar en el intrincado laberinto de palacio, para, una vez allí, topar con dos conceptos básicos de la cosmovisión cortesana y que marcan el ritmo de las formas de comportamiento cortesano: la prudencia y la discreción. Ambos conocimientos prácticos se orientan al gobierno de las acciones y del modo de proceder, eligiendo los medios proporcionados a la consecución de los fines ${ }^{35}$. Damasio de Frías y Balboa, en Diálogo de la discreción, distinguía ésta de la virtud aristotélica de la prudencia considerándola como un "hábito del entendimiento práctico mediante el qual obramos en las cosas agibles quándo y cómo, dónde y con quién y con las demás circunstancias que debemos y este hábito como tan universal que es participan de él los demás hábitos morales y

\footnotetext{
32 Gracián Dantisco, op. cit. (nota 2), p. 106.

33 Portugal, F.: Arte de la Galantería, Lisboa, 1670, p. 45.

34 Guevara, A. de: Aviso de privados y Doctrina de Cortesanos, Valladolid, 1545, fol. CLXXIII.

35 Álvarez-Ossorio Alvariño, op. cit. (nota 7, 2000), pp. 111-121.
} 
expeculativos" ${ }^{\prime 3}$. Este hábito tan universal que, con distintos acentos, resonó en la literatura áulica de los siglos XVI y XVII, actúa directamente sobre los comportamientos y las pautas para la civil conversación del Galateo, hasta tal punto que es el propio hábito de la discreción el que termina por caracterizarle ${ }^{37}$.

Precisamente de discreto (palabra omnipresente a lo largo de la obra) se calificaba a Galateo, el criado del Obispo Joan Matheo Gilberto de quién, supuestamente, el libro tomó el nombre ${ }^{38}$. El Tesoro de la lengua castellana de Sebastián de Covarrubias define discreción, piedra angular de la obra que nos ocupa, como "la cosa dicha o hecha con buen seso". De esta forma la carga semántica de discreto queda integrada dentro de discernir. Proveniente del verbo latino discerno, "vale vulgarmente distinguir una cosa de otra y hacer juicio dellas" -y continúa -"de aquí se dijo discreto, el hombre cuerdo y de buen seso, que sabe ponderar las cosas y dar a cada una su lugar" ${ }^{39}$. Así pues, distinguir, ponderar y -finalmente- dar son los pasos que guían el comportamiento del discreto. Dichas acciones las podemos diferenciar claramente en las recomendaciones dadas para la común conversación: si, como primeramente veíamos, el decoro imponía unas normas básicas (como evitar las palabras soeces y usarlas castas, honestas y biensonantes) acto seguido se completaban con una recomendación directriz "si no tuvieres en poco estos avisos, yo te aconsejo que quando hablares tengas cuidado de entender la voluntad con que es recebida tu plática, y mídela conforme al aplauso de los que te oyen" ${ }^{40}$. En otras palabras, el decoro y la gracia servían como primeras indicaciones para dar al cortesano la apariencia de poseer la gravedad y distinción necesarias y, por consiguiente, identificarlo como miembro del grupo de los privilegiados, pero, una vez dentro, el virtuosismo, la compostura o la gracia no bastaban para triunfar y por ello habrían de ser completadas mediante el recurso de la discreción, obligándole al Galateo a observar e improvisar constantemente para provocar el verdadero fin de sus actos, levantar el común aplauso que le permitiera ser bienquisto de aquellos con quién convivía y competía en sociedad.

Siguiendo la lógica de la discreción, al engalanarse, el cortesano camaleónico se atiene a las costumbres que observa acordes a su tiempo, manera y condición, no hacerlo "es contradecir a otros, y la contradición de usos y costumbres no se deve hazer sino en caso de necessidad, como diríamos después, porque esto nos puede hazer odiosos de la gente, más que otra qualquiera mala costumbre"41. Así, con palabras

36 Cito en Álvarez-Ossorio Alvariño, op. cit. (nota 7, 1999), p. 33. A lo largo de este artículo se pone en relieve la importancia del papel de la discreción en la literatura áulica hispana.

37 La discreción, no casualmente, es también protagonista en La Galatea de Miguel de Cervantes. Discretos son los personajes, las cartas, los discursos, las canciones, etc. Sin embargo, acorde a los cánones de la novela pastoril, son los aldeanos, especialmente las pastoras, quienes encarnan una nobleza natural, no aprendida, que iguala y supera a la de los cortesanos. Mientras que, por su parte, Lucas Gracián Dantisco vinculaba la discreción a selectas formas sociales. Véase Egido MArTínEz, A.: "El arte de la discreción en 'La Galatea"”, Bulletin of Spanish Studies: Hispanic Studies and Research on Spain, Portugal and Latin America, vol. 81, n. 4 (2004), pp. 585-598.

38 En realidad el nombre de Galateo parece derivado del nombre de Galeazzo (Galataeus) Florimonte, docto obispo y amigo de Della Casa. Véase, Morreale, M.: “El 'Galateo español' de Lucas Gracián Dantisco: una obra de cortesía en tono menor”, Boletín de la Real Academia Española, Tomo 42, (1962), pp. 47-90.

39 Covarrubias Orozco, op. cit. (nota 22), p. 717.

40 Gracián Dantisco, op. cit. (nota 2), p. 169.

41 Ibidem, p. 114. 
que recuerdan a las de Castiglione, recomendaba al noble seguir las pautas básicas, como guardar las armas, las mallas, las plumas y los penachos que los soldados usan en la guerra hasta la próxima contienda, si no quería resultar mal recibido por los ciudadanos de los pueblos pacíficos por parecerse a una ortiga entre las yerbas dulces y domésticas de los huertos ${ }^{42}$. Pero es al adaptarse a las cambiantes costumbres de las modas donde encontramos la quintaesencia de la discreción. Bajo la premisa "no tenemos poder para mudar el uso a nuestro parecer y antojo, antes devemos andar con el tiempo"43 debe el discreto Galateo permanecer constantemente observante de la evolución en la implantación de los nuevos usos y modas, sin querer distinguirse por adaptarla demasiado pronto o demasiado tarde porque ello supondría el hacerse destacar y contradecir, bien por novedoso o por antigualla. Así pues, observar, ponderar y finalmente, al llegar el momento adecuado, adoptar la nueva moda son las pautas que habrá de seguir un hábil cortesano para no dar nota de escándalo a nadie.

No obstante, las cosas podían volverse mucho más complejas. En las ceremonias parece repetirse la misma operación que al hilo de la discreción veíamos en conversación y vestiduras, $\mathrm{y}$, tras unas consideraciones sobre casuística, llega a la conclusión de que "es necesario que nosotros reconozcamos diligentemente los actos y palabras con las quales el uso y la costumbre moderno suele saludar y recebir o llamar, en la tierra donde vivimos" ${ }^{44}$. Así que, sigue aparentemente las pautas del discreto pero, en el camino seguido al dirimir esta cuestión, se introducen una serie de matices que conviene no obviar. Partidaria de la poca ceremonia, la obra observa y lamenta que los títulos y honras que los antiguos daban a las personas de calidad se dan ahora "sin

42 Ibidem, p.114. Esta extraña alusión sobre la vestimenta militar llama la atención especialmente por ser un pequeño parche ubicado, sorprendentemente, dentro del capítulo "De los que se dan a la poesía, sin tener partes bastantes" -uno de los incorporados por Gracián Dantisco-. Como ya se señaló anteriormente, la obra (a diferencia de la de Castiglione) no aborda los grandes debates sobre el linaje o sobre la condición militar de la nobleza, lo que hace más interesante ver como reconvierte el divertido pasaje perteneciente a ese mismo debate de El Cortesano en el que una dama ridiculizó a un fiero caballero de tan rudas costumbres que solo sabía pelear diciéndole: "Pues luego agora que no hay guerra ni hay para qué seáis, yo sería de parecer que os concertasen y os untasen bien, y, puesto en vuestra funda, os guardasen con los otros arneses para cuando fuera menester". El mantuano terminaba posicionándose a favor del cortesano de vocación militar con estas palabras tan similares: "aspero y fiero solamente cuando viere enemigos, hállase entonces siempre con los primeros; pero en cualquier otro lugar parezca manso y templado". Gracián Dantisco toma la anécdota -hecho casi seguro, pues a continuación continúan las semejanzas con la réplica de Pallavicino- lo que implícitamente deja la puerta abierta a estar describiendo un cortesano que sea noble y guerrero o que lo imita. Dada la diferencia de abolengo entre el noble mantuano y la familia humanista de Gracían Dantisco, no es de extrañar que el primero quisiera marcar distancias y el otro tomar parte del discurso, imitándolo, pero sin cargar especialmente las tintas en un debate que no le convenía. Algo similar le ocurre a Gracián Dantisco con la terminología que utiliza a la hora de traducir del italiano. Junto al término cortesano, que es inexistente en Della Cassa, adoptará una serie de términos que asocian al Galateo a términos amplios y populares como "gente de suerte y curiosa", "hombre honrado" o la adopción del término italiano gentilhombre. No obstante, por otro lado, no debe pasarnos desapercibido que también aluda ocasionalmente a nombres propios del estamento nobiliario como caballero, hidalgo, noble, etc. Esta versatilidad de términos deja entrever que exista una aspiración ennoblecedora en su discurso de Galateo Español y de mezcolanza con la difusa jerarquía y heterogeneidad de la baja nobleza urbana y cortesana. Sobre la composición del estado nobiliario: SoRIA MeSA, E.: La nobleza en la España moderna. Cambio y continuidad, Madrid, Marcial Pons, 2007. pp 37-43; Domínguez Ortiz, op. cit. (nota 21), pp. 19-145.

43 Ibidem, p. 116

44 Ibidem, p. 133. 
mirar los méritos, ni a la nobleza, ni al estado y calidad"45. Esta excesiva liberalidad que por fuera puede parecer buena, la considera vana y consistente en semblantes sin efecto y palabras sin significación. Por ello, cuando finalmente convenga que lo más acertado es no resultar enfadoso a los que ya acostumbran a recibir estos tratamientos y adoptar los usos en la forma en que el tiempo los ha desvirtuado, sentirá la necesidad de justificar el abandono de los hábitos que considera virtuosos alegando pobremente que "no es pecado nuestro, sino del siglo en que estamos" ${ }^{46}$. Aún más, sus iniciales recatos no son óbice para que se detenga ahí sino que da un paso más y termina recomendando para las ceremonias hacer igual que el buen sastre con el paño que corta para vestidos pues "antes le echa un poco sobrado que corto y escasso". De tal forma que "si tú usares en esto un poco de conveniente largueza, acerca de aquellos que son un poco menos que tú, serás llamado cortés; y mucho más si fuere algo más que tú, porque serás tenido por bien acostumbrado y plático gentilhombre" ${ }^{47}$. Un comportamiento extendido entre los curiosos y por el cual "por buena criança usan el día de oy de dezir: "Mi Señor Fulano", a sus amigos algo superiores; y especialmente, quando hablan con señoras y mugeres, o hijas de sus iguales, les dizen: "Mi Señora". Y con este lenguaje, se hazen gratos y benévolos a todos" ${ }^{48}$. El intenso contraste entre las posiciones iniciales y el punto de llegada no puede dejar de sorprender y, desde luego, cabe preguntarse hasta qué punto, bajo el paraguas de la discreción, Galateo Español se aparta de la búsqueda de la civilidad para introducirse en el terreno de la disimulación, simulación, e incluso si no llega realmente a llamar a las puertas de la lisonja.

El desplazamiento hacia la lisonja, que trataremos más adelante, supone un salto cualitativo no exento de polémica, pues se adentra en el oscuro terreno en que las virtudes degeneran en vicios, por ello lo que primeramente interesa es acotar los lazos que unían la discreción a la disimulación. Si, en un principio el mandato impuesto por el decoro conducía a ejercitarse en el arte de encubrir los instintos bajos y sujetar las pasiones (un requisito primordial de la buena crianza que hacía al hombre agradable en sociedad), el disimulo le llevará a ocultar sus sentimientos ante los demás o a encubrir lo que se quiere ejecutar a fin de facilitar la acción y prevenir los posibles obstáculos o contrariedades. Es decir, a distinguir, ponderar y acomodar, cualidades del discreto, hemos de añadir solamente la de encubrir para adentrarnos en el terreno del disimulo. La discreción, que elige los medios adecuados a las circunstancias, se

45 Ibidem, p. 131.
46 Ibidem, p. 131.
47 Ibidem, p. 138.

48 Ibidem, p. 138. La enfatización de dar un trato especialmente reverencial hacia las mujeres entra dentro de un código galante que reproduce e incrementa expresiones de servicio hacia la dama, siendo estas maneras entendidas como una seña más de buena crianza, desafortunadamente poco habituales en Galateo Español. Sin embargo, la intensa relación entre las buenas maneras cortesanas y las galantes queda patente en buena parte de la literatura áulica que, en ocasiones, la presentaba como un deber básico de todo cortesano. En palabras de Antonio de Guevara no servir dama sería más achacado a "cortedad que no a gravedad" mientras que el Galateo que se distinguiera en estas lides encontraría en la galantería, según Francisco de Portugal, un "oficio que acredita hasta al que no lo tiene". En la actualidad preparo la próxima publicación un trabajo que lleva por título "Los galanteos de Palacio: Aproximación a una práctica cortesana en la España de los Austrias"en que, a partir de la tratadística cortesana, desarrollará esta ligazón entre estas ciencias -la cortesana y la galante- y la posibilidad de entender sus códigos a partir de valores afines a ambas. 
sirve ocasionalmente de la técnica de la disimulación. De esta forma, sin apenas percibirlo, Gracián Dantisco cruza de forma habitual la tenue barrera que las separa. Así, si en la común conversación recomendaba al discreto Galateo "entender la voluntad con que es recebida tu plática, y mídela conforme al aplauso de los que te oyen" 49 a continuación pasaba a aconsejarle encubrir aquellas contrariedades engorrosas que podían desagradar al interlocutor como, por ejemplo, la conveniencia de disimular cuando otro estuviere equivocado y, en lugar de recriminarlo, sustituir expresiones como "vos os erráis", "no es verdad"o "no lo sabéis"por otras más cortesanas y dulces como "yo no me declaré bien"o "miremos bien si es ansí como vos dezís" ${ }^{50}$. Esta disimulación honesta quedaba loablemente justificada:

Porque es uso cortés y amable el desculpar a otro, aun en aquello que tú entiendes que tiene culpa. Antes se debe hacer común el error propio de tu amigo, y tomar primero una partezilla para ti, y después reprehendelle a su tiempo, diziendo: Nosotros erramos el camino y no se nos acordó de hazer esto, aunque sea verdad que la falta de memoria estuviese en el otro, y no en el que se mete en la culpa ${ }^{51}$.

De esta manera la vecina disimulación actúa como complemento a la discreción salvaguardándola de contrariedades y su relevancia se pone de manifiesto, de forma más o menos clara, en las diversas materias de la obra. Nuevamente, al igual que vimos en las ceremonias y en la conversación, en las vestimentas tenía cabida cierto tipo de inocente disimulación por decoro. A la regla general de no saltarse los usos comunes se hacen algunas salvedades que tienen por objeto el encubrir aquellos aspectos de la fisonomía que podían resultar feos o desagradables. Por consiguiente, con la finalidad de no entorpecer las posibilidades del Galateo siendo conocido por su amorfía, puede darse licencia a quienes tuvieren unas piernas muy largas o delgadas, deformes o tuertas, para que disimulen su defecto usando calzas de colores menos llamativos o alargando sus vestidos más de lo ordinario.

Con todo, mucho más allá del simple color de las calzas o una agradable apariencia, lo que realmente subyace bajo estos ejemplos es que, una vez que los comportamientos son subordinados al imperio de la discreción y no a la voluntad de convertir al hombre en un ser más virtuoso, se está dando pie a que una aplicación defensiva de la discreción pueda optar por disimular a fin de facilitar la acción y prevenir posibles obstáculos. Se entiende ahora mejor que, como veíamos al final del apartado anterior, al tiempo que se reconocía lo poco virtuoso de acciones como beber, jugar o burlar se hiciesen también las salvedades que el ejercicio de la discreción recomendaba. El alejamiento del virtuosismo que supone el paso al disimulo queda aún más patente al descubrir, recurriendo una vez más a Covarrubias, que disimular es no sólo "no darse por enterado de alguna cosa" sino como a continuación considera "bellaco disimulado, el que encubre su malicia" 52 . La diferencia es notable, la primera parte, más exacta, supone una cierta indolencia selectiva (como no querer darse cuenta de que

\footnotetext{
49 Gracián Dantisco, op. cit. (nota 2), p. 169.

50 Ibidem, p. 168.

51 Ibidem, p. 168.

52 Covarrubias Orozco, op. cit. (nota 22), p. 719.
} 
el acompañante erró el camino), mientras que la segunda parte alude abiertamente a encubrir, es decir, a cambiar la apariencia de lo real por lo ficticio. Esta segunda acepción, al convertir disimulación y simulación en sinónimas, no deja de entrañar un mayor riesgo moral puesto que implica la voluntad de querer hacer caer al otro en error y por tanto de engañar. La voluntad maliciosa por la cual se espera obtener beneficio propio o mal ajeno del encubrimiento será lo que nos arroje definitivamente hacía el terreno del vicio y del cual nos ocuparemos en el siguiente apartado.

\section{3. "Y amado de gentes": Los cantos de sirena, el beneficio de la gracia y el medro cortesano}

En una sociedad donde toda forma que pertenezca a un hombre tiene un valor social de representación, los cortesanos, con su sensibilidad exquisita para percibir las relaciones entre rango social y configuración de todo lo visible, estudiaban todos sus movimientos mientras observaban y emulaban a sus competidores, con los cuales libraban una incesante lucha de competencia por las oportunidades de status y prestigio $^{53}$. Arrastrados por los cánones que de ellos se esperaban algunos se esforzaban denodadamente -llegando más lejos que lo recomendado en Galateo Español- por disimular algunos defectos, como Luis de Zapata, quién, por ser grueso, reconocía haber pasado grandes privaciones con la comida, llegando a vendar su cuerpo y vistiendo tan justo que "era menester descoserme las calças a la noche para quitármelas, y cuando había sarao y dançar con las damas a la noche en palacio, porque la cama enflaquece las piernas, me acaeció muchas veces para las llevar delgadas estarme en la cama todo el día, con lo que al fin salí, gracias a Dios, de mi intento". Otras, como Felipa de Mendoça, no dudaron en comer arcilla para mantenerse pálidas ${ }^{54}$. Con todo, cabe pensar que, a merced de estos esfuerzos por emularse y disimular, los cortesanos debían parecerse mucho los unos a los otros, y, en efecto, eso parece deducirse de las palabras de un extranjero que, según Gracián Dantisco, sentenció que "en España, casi todas la mugeres eran altas, blancas y rubias por su natural o por su artificio". Artificio de las españolas del que andaba menos avisado otro extranjero, del cual también nos habla:

Otro déstos dezía, que las españolas tenían su fundamento en cumplimientos y apariencias solamente. Porque quando se casó le dieron mujer blanca, rubia y bien dispuesta, y salióle no más de media muger, y sin ningún cabello, tanto que la noche de la boda vio que la mitad della era de corcho dorado, y se la pusieron debaxo de la cama; y la otra mitad de muger que le quedó encima de la cama, la halló a la mañana verdinegra, flaca, calva y descolorida; y por esto se llamava a engaño en más de la mitad de la muger. ${ }^{55}$

53 Elias, N.: La sociedad cortesana, México, Fondo de cultura económica, 1982, p. 88.

54 Bouza Álvarez, op. cit. (nota 7, 2003), pp. 82-83.

55 Gracián Dantisco, op. cit. (nota 2), pp. 139. 
Esta cómica anécdota del masculino desengaño, pese a su aparente trivialidad, pone en la senda de una de las principales tensiones de la sociedad cortesana: la habilidad de ocultar los impulsos, dándoles el disfraz de lo grato, entra abiertamente en liza con la, igualmente importante, habilidad de observar y escudriñar qué hay realmente de verdad bajo la falsa apariencia. El Galateo habría de considerar que la discreción no solamente consistía en saber despertar los aplausos ajenos sino que encomendarse a ésta, como habilidad consistente en discernir, supondría disponer de una suspicaz salvaguarda de los perniciosos efectos de la disimulación ajena. Las expectativas cortesanas puestas sobre la gracia y liberalidad de su señor bien pueden quedar en, la también muy cortesana, decepción si no advertían certeramente los peligros de lisonjas, trampas u ocultamientos con que otros aspiraban truncar la pretensión propia. Por ello, por medio del desdichado marido, da alerta sobre aquellos personajes dados a engolosinar la realidad y "que consisten en hechos también fingidos, con solas apariencias" ${ }^{56}$.

Así las cosas, si anteriormente, al tratar de las ceremonias, veíamos como se recomendaba adoptar las ceremonias que el uso había impuesto y, tras numerosas tribulaciones, aconsejaba poner algo de más de tal manera que el Galateo se guardara de dar pie a cualquier disconformidad e, incluso, hacerse grato y benévolo por su largueza. Encontramos ahora su reverso al señalarse "las ceremonias vanas y superfluas son adulaciones claras" ${ }^{57}$ con las que el lisonjero trata de conquistar al ingenuo que se paga de ellas. Este lisonjero actúa como un camaleón "que se transforma en el color del lugar que le ponen, assí también estos tales se contrahacen en forma de amigos, según nuestras voluntades, cualesquiera que sean, no porque nosotros lo queramos, sino para que les demos algo, y no para agradarnos, sino para engañarnos" 58 . La sutileza que sirve en esta ocasión para distinguir entre adulador y Galateo reside en que al primero se le achaca un ánimo escondido en virtud del cual se haya interesado hacerse grato y benévolo. El supuesto fraude pergeñado por el adulador es condenable y, mediante una enigmática coletilla, desecha su aplicación solamente como no conveniente puesto que "mentiras y lisonjas, quantas vezes las usamos por manera de ganancia, tantas vezes obraremos como hombres malos y desleales" ${ }^{59}$.

Ciertamente que la sutil diferencia de la buena cortesanía del Galateo Español que usa de formas modestas, gentiles y dulces, que no tengan ningún sabor amargo para "incitar en tu loor y estima la voluntad y benevolencia" 60 - con las reprochables lisonjas del adulador podía resultar difusa en ocasiones, en la misma medida que la buena cortesanía tampoco se encuentra vacía de interés y beneficio. Algo que, al menos formalmente, se prefiere obviar pasándose de largo cualquier consideración sobre el papel jugado por la recompensa de la gracia y liberalidad (es decir, ese mismo código servicio-merced que tomábamos al comienzo del artículo como caracterizador de la cortesanía). Sin embargo, la misma prevención sobre aquel cuyas nefastas intenciones buscan introducir el dolo para su provecho, supone un reconocimiento

\footnotetext{
56 Ibidem, p. 139.

57 Ibidem, p. 139.

58 Ibidem, p. 132.

59 Ibidem, p. 132.

60 Ibidem, p. 105.
} 
implícito de ser consciente de los beneficios que deportaba el cultivo de las buenas maneras. En este sentido cabe señalar como la expresión "amado de gentes", con que pronto se acompañaría a la obra, indicaba que el lector que guardara las pautas propuestas sería nada menos que el ser amado o, dicho con otras palabras, el receptor del amor del que ama. Llegar a serlo deportaría al lector los enormes beneficios de la gracia, pero antes de ello habría que salir triunfante entre los vicios cortesanos -la malicia, la envidia, el fingimiento, la zalamería, etc.- sin abandonar de forma clara los francos y loables principios que el modelo cortesano defendido decía perseguir. Ello suponía, desde el punto de vista del autor de manuales áulicos, recurrir a un gran malabarismo que permitiese ingeniárselas para, reconociendo la ilicitud de la mentira y la simulación, prevenir los nocivos peligros de la osada sinceridad y benevolencia en un medio hostil. Al fin y a la postre, dado que pretender conciliar el sincero virtuosismo con cierto grado de discreto fingimiento tenía bastante de contrasentido, no es de extrañar que los tratadistas recurriesen comúnmente a útiles ambigüedades o ambivalencias, las cuales quedan totalmente delatadas una vez que se contrastan las diferentes formas en que se sorteaba tan peliaguda cuestión.

La Filosofía Cortesana de Alonso de Barros, una obra que veía la luz en fechas similares, tiene la originalidad de tratarse de una suerte de "juego de la oca" cuyas 67 casillas se dedican a los avatares propios de la vida cortesana y cuya finalidad es enseñar el camino para triunfar en la corte. En otras palabras, para conseguir "la pretensión que cada uno lleva". De este juego, gracias a su esfuerzo racionalizador, nos interesa que al llegar a la casilla 39 el jugador tropezaba con la falsa amistad de aquellos que "se hazen muy humildes y fáciles de trato" (palabras que perfectamente hubieran podido usarse para definir al Galateo) hasta que toman lo que quieren, para con los cuales se recomendaba "disimular con ellos; y para no hazer de amigos enemigos, ni dar lugar a que del todo se declaren por tales, mostrando satisfacción de su voluntad". Mientras el primero es recriminado por encubrir su pretensión bajo el disfraz de lo grato, al segundo se le recomienda disimular mostrándose agradecido para salvaguardar la suya, con unas palabras que recuerdan enormemente la definición de camaleón que daba Galateo Español. No denunciando ni dándose por enterado del ardid que contra él trama el falso amigo, evitará un enfrentamiento que dañe su propia pretensión. Siguiendo la lógica del juego, y esto es lo más curioso, el desdichado jugador que cayó en la trampa del adulador retrocede hasta la séptima casilla en la que se "manda al negociante que vuelva a ser pródigo con los que tuuo antes por sospechosos, que al principio todos lo son, hasta que se topan otros peores" ${ }^{\prime 61}$.

También ilustrativo de esta ambigüedad y ambivalencia es el caso que se encuentra en la casilla 43, dónde se halla la mudanza de ministros, por lo que el pretensor debe de volver a la número 10 que, no casualmente, se dedica a la adulación. Si volver a la adulación -palabra con la que Sebastián de Covarrubias definía la lisonja- no fuera

61 Para Filosofía Cortesana de Alonso Barros, véase Collar DE CÁCERES, F.: "El tablero italiano de la Filosofía cortesana de Alonso de Barros (1588); la carrera de un hombre de corte", en Anuario del Departamento de Historia y Teoría del Arte, no 21, (2009). pp. 81-104; y Martínez Millán, J.: "Filosofía Cortesana de Alonso de Barros (1587)", en Fernández Albaladejo, P., Martínez Millán, J. y Pinto Crespo, V.: Política, religión e inquisición en la España moderna: homenaje a Joaquín Pérez Villanueva, Madrid, Universidad Autónoma de Madrid, 1996, pp. 461- 482. 
suficientemente expresivo, la imagen de la casilla es la de una sirena con un espejo en una mano y en la otra un camaleón, porque el adulador, como las sirenas, con su canto y su plática atrae "para matar por engaño" y, cómo el camaleón, "muda en diferentes figuras, llevando el gusto del engañado, como se muda el camaleón de color de lo que está cerca".

Que Galateo Español, un libro de buenas maneras, no aborde y, es más, ni siquiera mencione los ministros y validos del señor, podría conducirnos a pensar que nos adentramos en un terreno diferente y que excede el sentido de la obra. Sin embargo, el que llegaba a la casilla dedicada a la mudanza de ministros encontraba la siguiente explicación: "aviendo el pretensor granjeado con todas sus fuerças algún personaje, ministro de su negocio de que pensaba valer, se le muda, con lo qual se halla falto de acogida, por ser solo que le es fuera decir: "Quien limita su esperança, sufra el golpe de mudança"'. Por tanto, entendemos como en la sociedad de corte, en que no existe una diferenciación entre lo público y lo privado, cobra una importancia renovada la capacidad del Galateo, que no limita su esperanza y, como reza el título de la obra, es conocedor de los entresijos de lo que se debe hacer "para ser bien quisto y amado de las gentes".

Aunque difícilmente con la transparencia y claridad de Alonso de Barros, existen otros muchos ejemplos de estas mismas realidades como es el caso del coetáneo y siempre disgustado Conde de Portalegre quien podía presumir de, a lo largo de sus más de cuatro décadas viviendo en palacio, haberse convertido en un auténtico experto en ministros, validos, hechuras y todo tipo de relaciones personales que albergaba el mundo de la corte. Por ello, aconsejaba a su hijo que la mejor manera de tratar a los privados era sufrirlos con disimulación hasta granjeárselos con decoro y presteza. ${ }^{62}$ Así pues, ya sea en Alonso de Barros, Juan de Silva o Gracián Dantisco vemos que para moverse por palacio, para triunfar en la corte o para lograr la pretensión, convenía gobernarse como discreto Galateo, disimulando cuando fuere preciso para hacerse grato y despertar la benevolencia de toda aquella persona que pudiese. Pero también en todos ellos, de forma más o menos clara, podemos entrever la presencia del reconocimiento de que, en ocasiones, para lograr estos objetivos, se hacía preciso cierto tipo de ocultación y falsía.

En último término, aunque resulte fascinante, no se pretende aquí desentrañar los pormenores de hasta dónde podían llegar los medios cortesanos antes de arrojarse abiertamente al engaño y al dolo, ni cómo de la mano de estas dobleces los detractores de la vida áulica extendieron una acepción peyorativa del término cortesanía cuya asociación a las intrigas, la lisonja y la adulación perdura, aún en nuestros días, en el imaginario colectivo. ${ }^{63}$ Lo que interesa resaltar es cómo una vez reconocido que una ligera hipocresía podía esconderse bajo las agradables y dulces maneras cortesanas, éstas, lejos de ser entendidas como un mero ornamento superfluo, eran vistas como un medio merced al cual el pretensor cortesano bien podía encontrar su salvaguarda o su perdición. Por ello, para conseguir una y evitar otra el Galateo debía recurrir a

62 Bouza Álvarez, F.: "Corte es decepción. Don Juan de Silva, Conde de Portalegre", en Martínez MiLLÁN, J.: La corte de Felipe II, Madrid, 1994. pp. 487.

63 BurKe, op. cit. (nota 27), pp. 119-137. 
encaminar sus acciones por medio de la discreción y, llegado el caso, a cierta disimulación.

\section{Hacia una nueva lectura del Galateo}

Bien pudiera señalarse ahora, una vez terminado nuestro camino, la grotesca historia de Critilo y Andrenio, quienes -en la crisis undécima de El Criticón de Baltasar Gracián- deciden buscar en una librería de la calle de Toledo un manual que les permita encontrarse dentro del laberinto de la Corte. El cortesano que allí hallan, testimonio de toda una generación desengañada, no puede dejar de soltar una enorme risotada al ver que el librero les ofrece la obra de Gracián Dantisco y, desaconsejándoles comprarla, les advierte "así como tiene algunas reglas superfluas, otras tiene muy frías". Una vez descartada ésta por tratarse de un sencillo manual de cómo sonarse la narices, el librero prueba de nuevo suerte con las reglas cortesanas de Vega-Silva: "pues si no os contenta, dijo el librero, porque instruye sino en cortesía material, no da sino una capa de personas, una corteza de hombres; aquí esta la juiciosa y grave instrucción del prudente Juan de Vega a su hijo cuando le enviaba a la Corte" ${ }^{64}$. Finalmente, terminan por adquirir las Instrucciones pero como también es poca la utilidad que le encuentran la ignoraran como al Galateo Español. El error en el que sus personajes estaban incurriendo quedaba posteriormente aclarado por el autor jesuita cuando, posteriormente, Critilo mantiene un enconado debate con aquella musa no dispuesta a dejar que aparte ambos libros de aquellos otros que el advenedizo consideraba de grave política y no de mera corteza de hombres. Ésta porfiaba que la obra se quedaba en su lugar puesto que responde "a la política de cada uno, a la razón especial de ser personas" ${ }^{65}$. Lo singular de esta historia escrita con el descarnado estilo de Baltasar Gracián es que, en buena medida, refleja algunos de los tópicos aún hoy prevalecientes que ven en la famosa obra de Lucas Gracián Dantisco una mera corteza de hombres. Por ello, en este trabajo se ha tratado de desentrañar el particular papel de la discreción como conductora de la "política de cada uno".

Así las cosas, gran parte de la genialidad del binomio Della Casa-Gracián Dantisco residía en la brillante delicadeza con que unía la tradición en materia de buena crianza heredera de De civilitate morum puerilium de Erasmo con el modelo de sprezzatura y cortesanía virtuosa de El Cortesano de Castiglione, al mismo tiempo que, siguiendo su propia visión marcadamente práctica y preventiva, de la mano de sus preceptos de buenas maneras introducía una ciencia aproximativa basada en el universal hábito de la discreción con la cual salir triunfante de palacio, conservando y aumentando su hacienda y honor. Abriendo las puertas del laberinto de palacio, "Gracián, de discreción perfecta llave" ${ }^{66}$ (como aseveraba el soneto del licenciado Gaspar de Morales que abría la obra) aleccionaba y prevenía al aprendiz de cortesano sobre los peligros del disimulo, la lisonja, el desengaño, etc. Tan solo la constatación de la presencia de

64 Gracián, B.: El Criticón [Ilustraciones de Antonio Saura, Introducción de Aurora Egido, Colofón de Miquel Batllori, Texto fijado y anotado por Carlos Vaíllo], Barcelona, Galaxia Gutenberg, 1964. pp. 90-93.

65 Ibidem, p. 143.

66 Gracián Dantisco, op. cit. (nota 2), p. 102. 
términos como desengaño implica que se ha tomado conciencia de la posibilidad del embuste y la utilización perversa del método cortesano y, por consiguiente, decídase o no su utilización por parte del Galateo, pone en cuestión aquella tradición occidental previa que quería ver en la corporeidad y gesto de los individuos una manifestación de sus caracteres y alma. Con todo, concluyendo el presente trabajo, no puede pasar desapercibido al historiador que, lejos de ser una obra de cortesía "ingenua" o de "tono menor", Galateo Español debe ser tratada como una obra trascendente para el estudio de la sociabilidad cortesana que, guardándose de dar motivo de disconformidad alguna, aleccionaba tan sutil y discretamente que, al hacerlo, guardaba una de sus principales máximas: "aun con mayor cuidado de no dar nota ni escándalo de ti a nadie" $"$.

67 Ibidem, p. 178. 